\title{
Monoclonal Antibody Therapy: Breakthrough in Migraine Preventive Therapy
}

\author{
I Made Oka Adnyana ${ }^{1}$, Faldi Yaputra ${ }^{1}$ \\ ${ }^{1}$ Department of Neurology, Faculty of Medicine, Universitas Udayana, Bali, Indonesia. \\ Corresponding Author: I Made Oka Adnyana (oka_adnyana@unud.ac.id)
}

DOI: https://doi.org/10.52403/ijrr.20220254

\begin{abstract}
Preventive medicine is appropriate for the majority of patients, including migraine patients, since migraine is considered a chronic condition that causes debilitating headaches that impair quality of life. Oral migraine preventive medications are available, but their use is restricted owing to their side effects and the fact that they are not specifically intended for migraine prevention. The currently available monoclonal antibodies (all have been approved by the Federal Drug Administration (FDA)) were developed specifically for the prevention of migraine and specifically targeted the CGRP peptide, which plays a critical role in the migraine mechanism. Thus, we discussed the breakthrough in migraine prevention in this article, with a particular emphasis on the role of monoclonal antibodies.
\end{abstract}

Keywords: migraine prevention, monoclonal antibodies, CGRP

\section{BACKGROUND}

Migraine is one of the most prevalent headache disorders globally. According to the World Health Organization (WHO), migraine is the most often reported neurological condition that leads in disability. ${ }^{1}$ However, the exact mechanism of migraine pathophysiology remains unknown. At the moment, the only acute migraine therapy developed specifically for migraine is the triptan drugs, which is known to have vasoconstriction properties, in accordance with existing theories about migraine being vascular disorders. $^{2}$
Based on data from the WHO, expressed as cause-specific disabilityadjusted life years (DALYs), migraine rank $29^{\text {th }}$ worldwide. In Southeast Asia, migraine rank $33^{\text {rd }}$ cause of DALYs. In women, migraine rank $19^{\text {th }}$ out of all causes of DALYs, and ranks $41^{\text {st }}$ in men. Based on the latest epidemiological developments from WHO data, in the last 15 years, migraine have become a considerable burden to cause disability. ${ }^{3}$

In the United States, the prevalence of migraine reaches $12 \%$ of the total population, of which $18 \%$ consists of women, and $6 \%$ of men. The data also showed that migraine was followed by various comorbid diseases, such as cardiovascular disease, psychiatric diseases, and sleep disorders. This resulted in migraine ranking second as the most common disorder leading to disability globally, having a significant impact on an individual's work, education, social, family, and personal life. ${ }^{4}$ According to Adnyana (2012), one of the universities in Bali has a $27 \%$ greater frequency of migraine than the general population, which would undoubtedly affect the productivity of its participants in carrying out education. ${ }^{5}$ High levels of CGRP in serum were significantly associated with the incidence of increased tension headaches, according to Adnyana et al. (2020) who conducted research on medical school students in Bali. ${ }^{6}$

Preventive medications have just recently begun to be extensively developed and investigated. However, no specific drug 
for migraine prevention has been developed among the various preventive migraine treatments. Preventive medications for migraine are currently extensively used, although they are treatments designed for other illnesses, which have numerous limits and negative effects. This laid the groundwork for the creation of drugs that work specifically to prevent migraine recurrence. A lot of research has been done on migraine medications that work specifically to prevent migraine. We will review some of monoclonal antibodies that work on CGRP.

A neuropeptide, Calcitonin generelated peptide (CGRP), demonstrates an important role in the trigeminothalamic pathway that channels nociceptive signals in the head region. Some studies show CGRP levels increase in the externa jugular vein during a migraine attack, and levels decrease with reduced headaches. Other studies have also shown that CGRP injection is able to trigger migraine attacks. On this basis, CGRP is thought to have a central role in modulating pain, where CGRP plays a role in neurovascular pathways and contributes to vasodilation and neurogenic inflammation leading to migraine attacks. ${ }^{7}$

\section{Migraine Pathophysiology}

According to the International Headache Society, the diagnostic criteria for migraine are headache for 4-72 hours, with a minimum of 2 of the following symptoms: unilateral pain, throbbing quality, moderate intensity, aggravated by movement and accompanied by nausea, vomiting, photophobia, phonophobia. ${ }^{8}$ Migraine is classified into four stages based on the symptoms: prodrome phase, aura phase, attack phase, and postdrome phase. ${ }^{9}$

Migraine is not just vascular disorders; they are neurovascular disorders in which neuronal abnormalities lead to pain and nervous system activation. The ophthalmic branch of trigeminal nerve becomes the primary channel for afferent fibers delivering pain from the supratentorial structure and the anterior area of the head. Unmyelinated $\mathrm{C}$ fibers innervate the pain-sensitive structure with neurotransmitters such as substances $P$, CGRP, and neurokinin A, going via the trigeminal ganglion to the pons and reaching the spinal trigeminal nucleus. ${ }^{11}$ Spinal trigeminal nucleus extends downwards and joins C1-C3 segments of the spinal nerves and send signals to the thalamus, the autonomic nucleus in the pons (superior salivatory nucleus), and the hypothalamus. ${ }^{12}$

Migraine mechanisms include the occurrence of brain dysfunction of peripheral and central nervous system components mediated by trigeminovascular pathways resulting in the release of inflammatory mediators that stimulate pain. This peripheral mechanism being one of the basic treatment of migraine that does not require drugs that are able to cross the blood-brain barrier. ${ }^{12}$ Recent studies have shown areas of the brain stem, dorsolateral pons, periaqueductal gray matter and hypothalamus were observed to be active before the onset of migraine occurred. ${ }^{13}$

Serum CGRP levels in the external jugular vein increased during the migraine attack phase, but not other neuropeptides, and subsequently decreased as symptoms resolved. Infusional delivery of CGRP has been shown to induce headaches, followed by symptom alleviation. ${ }^{12,14}$ This opens up new pathways in migraine therapy.

\section{Calcitonin gene-related peptide (CGRP)}

Calcitonin gene-related peptide (CGRP), a vasodilator, composed of 37 amino acid neuropeptides, belonging to the calcitonin group identified in $1983 .{ }^{14}$ Calcitonin, amylin, two CGRP, and adrenomedullin are all members of the calcitonin peptide family. Although they are derived from the same source, calcitonin and CGRP have distinct physiological functions. CGRP is considered a regulator of vascular hemostasis, although recent research indicates that it may also play a significant role in nociceptive transmission, whereas calcitonin is involved in calcium 
hemostasis and bone remodeling. ${ }^{7,12,14}$

Calcitonin gene-related peptide is a long-acting vasodilator neuropeptide that is located in the walls of cerebral and cardiac blood vessels and contributes to cranial blood vessel vasodilation. CGRP is also generated immunochemically by the dorsal and ventral radix neurons. ${ }^{11}$

Calcitonin gene-related peptide is present in all organ systems of the body, it has 2 forms, $\alpha$-CGRP and $\beta$-CGRP. $\alpha$ CGRP is the main form expressed in the trigeminal nerve ganglia formed in chromosome $11 .^{12,14}$ It is composed of $\mathrm{N}$ terminal disulfide, $\alpha$-helix, and phenylalanyl amide $\mathrm{C}$-terminus bridges. $\beta$-CGRP is coded on separate genes, and is found in the nerves of the digestive system and pituitary gland. It may play a role in the mechanism of gastroparesis and other gastrointestinal problems associated with migraine. This article will focus on $\alpha$-CGRP, which we will brief in this article as CGRP. ${ }^{12}$

Predominantly CGRP is expressed in the nociceptive nerve, $\mathrm{C}$ and A delta fibers. It is widely distributed in the central and peripheral nervous systems. Peripherally, CGRP is abundant in posterior horn cells stored along with substance $\mathrm{P}$ in the sensory nerve ganglion, and alongside acetylcholine in motor nerves. In the central nervous system, CGRP acts on second- and thirdorder nerves in modulating pain transmission and is present throughout the body of nerve cells in the preoptic area, hypothalamus, ventromedial thalamus, medial amygdala, hippocampus, superior colliculus, lateral lemniscus, dentate gyrus and Purkinje cells in the cerebellum. The highest density of nerves expressing mRNA CGRP is conserved throughout the cranial nerve nucleus, with the exception of the posterior motor nucleus of the vagal nerve (X). ${ }^{12}$ It has been proven that trigeminal ganglion stimulation in humans results in the release of CGRP and substance $\mathrm{P}$, but substance $\mathrm{P}$ has no role in migraine pathophysiology. When a migraine episode occurs, CGRP levels increase but substance $\mathrm{P}$ levels remain constant; however, the increase in CGRP levels can be reversed following sumatriptan treatment. ${ }^{13}$ In contrast, intravenous injection of CGRP triggers migraine attacks. ${ }^{7}$

Pathophysiology migraine relates to the location of the CGRP and its receptors. Calcitonin gene-related peptide is expressed in unmyelinated nerve fibers, but CGRP receptors are expressed in myelinated nerve fibers and blood vessel walls. Calcitonin gene-related peptide and its receptors are also found in other locations such as the spinal trigeminal nucleus and the $\mathrm{C} 1 / \mathrm{C} 2$ segment of the spinal nerves. Location of CGRP production is different from the location where CGRP works. ${ }^{12}$ The trigeminovascular system contains a significant amount of CGRP, making it a vital area for the migraine process. ${ }^{11}$

In comparison to other mediators such as substance $\mathrm{P}$, vasoactive intestinal peptide (VIP), neuronal nitric oxide synthase (nNOS), and pituitary adenylate cyclase-activating polypeptide, CGRP is the most abundant neuropeptide in the animal duramater and trigeminal ganglion (PACAP). ${ }^{12}$ However, only CGRP and PACAP tested positive for radioimmunoassay during a migraine attack. ${ }^{13}$ CGRP levels also increase in other forms of headaches, including cluster headaches and persistent paroxysmal headaches, but are followed by an increase in vasoactive intestinal peptide (VIP). ${ }^{15}$

The primary function of CGRP in various body systems is still under investigation. It is known that these peptides have variety of biological effects on a particular tissues, including cardiovascular, smooth and striated muscles, and the endocrine and gastrointestinal systems through activation of specific receptors on the plasma membrane. ${ }^{12}$ CGRP levels in plasma, saliva, and cerebrospinal fluid are reported to rise during a migraine episode. Increased CGRP concentrations in CSF fluid indicate that CGRP is also delivered into the central nervous system via trigeminal nerve. ${ }^{15}$ 


\section{The Role of CGRP in the Trigeminovascular System}

In the central nervous system, CGRP plays a role in modulation and perception of pain as well as central sensitization. CGRP amplifies the release of substance $\mathrm{P}$ from terminal afferent fibers triggers nociceptive transmission induced by pain stimulus. CGRP also modulates the transmission of glutamate and acetylcholine in synapses. ${ }^{13}$ The release of CGRP in the peripheral from trigeminal fibers gives rise to vasodilation and degranulation of mast cells, resulting in sensitization of trigeminal nociceptors. CGRP works by paracrine patterns, depolarized nerve cells and surrounding glial cells and induces CGRP synthesis on their own. This cascade supports the role of CGRP in the development and maintaining central and peripheral sensitization in migraine pathophysiology. ${ }^{12}$ The brain stem and trigeminovascular complex have been extensively studied, which explains how the brain stem contributes to the migraine process. ${ }^{13}$

At the moment, numerous techniques are used to target CGRP. Among these is the CGRP receptor antagonist, which employs a tiny chemical (CGRP-RA) that competes with CGRP for binding to its receptors. Monoclonal antibodies (mAbs) that recognize and neutralize CGRP's biological activity can also be used to target free CGRP and CGRP receptors. ${ }^{11,14} \mathrm{We}$ will focus on anti-CGRP monoclonal antibodies.

\section{Anti-CGRP Monoclonal Antibody (mAbs)}

Monoclonal antibodies, which are created by a single cloned cell, were first used therapeutically in 1982, when patients with lymphoma responded completely to antibodies (made by mice) directed against their tumor cells. Until the last two decades, the use of monoclonal antibodies (mAbs) was dramatically increased, with more than 20 mAbs licensed for use against humans by the Federal Drug Administration (FDA). ${ }^{14}$ There are now four monoclonal antibodies directed against CGRP and CGRP receptors; all four antibodies have been approved by the FDA for use as a migraine preventive therapy. ${ }^{16,17}$ Anti-CGRP Monoclonal antibodies (mAbs) are made of proteins that are unable to penetrate the blood-brain barrier. Intravenous, subcutaneous, or intramuscular lines are preferable due to their high hydrophilic nature, which makes absorption via oral routes more difficult. ${ }^{12}$ Due to its prolonged duration of action, it is appropriate for use as a prevention medication for chronic headaches. In comparison to abortive migraine medication administered 1-2 times daily, the administration might be done once a month. ${ }^{11}$

These antibodies are normally eliminated by the kidneys or the liver, without being processed in the liver, and hence do not cause hepatotoxicity. ${ }^{11,13}$ Concerns about these drugs' safety in migraine are mostly related to their CGRP inhibition and antibody infusion effects. Cardiovascular adverse effects are a concern because of CGRP's vasodilator characteristics. These include medicationinduced hypertension, pharmacological interactions, and suppression of stress- or ischemia-induced coronary vasodilation. ${ }^{13}$

Galcanezumab, eptinezumab (ALD403), and fremanezumab are three anti-CGRP monoclonal antibodies for humans that are now undergoing clinical studies and have been shown to be effective as migraine deterrents. Additionally, monoclonal antibodies targeting the CGRP receptor, erenumab, were discovered (AMG334). ${ }^{15}$ The four monoclonal antibodies have a common mechanism of action that prevents CGRP from attaching to its receptors.

\section{Erenumab}

Erenumab

(AMG334, AIMOVIGTM), immunoglobulin G2 (IgG2), is an anti-CGRP receptor monoclonal antibody that works by inhibiting the fusion of extracellular proteins CALCRL and RAMP1. Erenumab 
binds to CGRP receptors with a high affinity, both in vitro and in vivo. Erenumab has been demonstrated in clinical trials to be beneficial as a preventive medication for chronic and episodic migraine. ${ }^{15}$ Erenumab is the first monoclonal antibody to be FDAapproved as a migraine preventive therapy in 2018. ${ }^{8,18}$ Because the half-life is 28 days, it is suggested to administer $70 \mathrm{mg}$ subcutaneously once a month. ${ }^{19}$ After three months, erenumab achieves steady plasma levels. Erenumab is an injectable medication that may be administered into the belly, thighs, or upper arms. Available in an injectable version that patients can administer themselves. ${ }^{19}$ The most often reported adverse events were reactions to the injection site (5\%), constipation (1-3\%), and muscular cramps $(2 \%){ }^{20}$

\section{Eptinezumab}

Eptinezumab

(ALD403,

VYEPTITM), immunoglobulin G1 (IgG1) is a genetically modified antibody that is administered intravenously once every three months. The only anti-CGRP monoclonal antibody available for intravenous infusion. ${ }^{15}$ After completing through a phase of clinical studies since 2012, Eptinezumab got FDA approval in February 2020, as a migraine preventive medication in adults. The suggested dose is $100 \mathrm{mg}$ every 3 months using an intravenous line, some individuals need a dose of $300 \mathrm{mg}$ to acquire effective results. ${ }^{17}$
In phase III clinical studies, the most frequently reported adverse events were nasopharyngitis $(6 \%$ at $100 \mathrm{mg}$ and $8 \%$ at $300 \mathrm{mg}$ doses), hypersensitization (1\% at $100 \mathrm{mg}$ and $2 \%$ at $300 \mathrm{mg}$ doses). ${ }^{17}$

\section{Fremanezumab}

Fremanezumab

(TEV-48125, AJOVYTM) is an immunoglobulin G2a (IgG2a) that is administered subcutaneously once a month. Since 2006, fremanezumab has been in preclinical testing; in 2010, it entered the first phase of clinical trials; and in late 2018, it received FDA approval as a migraine preventive treatment. Available in three formulations: $225 \mathrm{mg}$ (once a month), $675 \mathrm{mg}$ (once every three months), and 900 mg (once every three months), all of which are administered subcutaneously. ${ }^{21}$

\section{Galcanezumab}

Galcanezumab (LY2951742) is an immunoglobulin G4 (IgG4) that is administered subcutaneously once a month. ${ }^{13}$ Galcanezumab obtained FDA approval as a migraine preventive therapy in adults in September 2018 after beginning the clinical trial in 2011. The suggested dose is $240 \mathrm{mg}$ (divided in two consecutive 120 $\mathrm{mg}$ injections) for the first month as a loading dose, followed by a monthly dose of $120 \mathrm{mg}^{22}$ Following discontinuation of medication, drug levels decline but do not return to baseline, and migraine symptoms do not return to baseline. ${ }^{23}$

Table 1. Monoclonal Antibodies for Migraine Prevention ${ }^{15}$

\begin{tabular}{|c|c|c|c|c|}
\hline No. & Drug & Indication & Dose & Mechanism \\
\hline 1. & $\begin{array}{l}\text { Erenumab (AMG } \\
334)\end{array}$ & $\begin{array}{l}\text { Episodic migraine prevention and } \\
\text { chronic migraine }\end{array}$ & $1 \mathrm{x} /$ month, subcutaneous injection & $\begin{array}{l}\text { Anti-CGRP receptors } \\
\text { monoclonal antibodies }\end{array}$ \\
\hline 2. & $\begin{array}{l}\text { Galcanezumab } \\
\text { (LY2951742) }\end{array}$ & $\begin{array}{l}\text { Episodic migraine prevention, chronic } \\
\text { migraine, episodic cluster headache, } \\
\text { chronic cluster headache. }\end{array}$ & $1 \mathrm{x} /$ month, subcutaneous injection & $\begin{array}{l}\text { Anti-CGRP } \\
\text { monoclonal antibody }\end{array}$ \\
\hline 3. & $\begin{array}{l}\text { Fremanezumab } \\
\text { (TEV-48125) }\end{array}$ & $\begin{array}{l}\text { Episodic migraine prevention, chronic } \\
\text { migraine, episodic cluster headache, } \\
\text { chronic cluster headache. }\end{array}$ & $\begin{array}{l}1 \mathrm{x} / \text { month or } 1 \mathrm{x} / 3 \text { months, } \\
\text { subcutaneous injection. Intravenous } \\
\text { injection for cluster headache }\end{array}$ & $\begin{array}{l}\text { Anti-CGRP } \\
\text { monoclonal antibody }\end{array}$ \\
\hline 4. & $\begin{array}{l}\text { Eptinezumab } \\
\text { (ALD403) }\end{array}$ & $\begin{array}{l}\text { Episodic migraine prevention and } \\
\text { chronic migraine }\end{array}$ & $1 \mathrm{x} / 3$ months, intravenous infusion & $\begin{array}{l}\text { Anti-CGRP } \\
\text { monoclonal antibody }\end{array}$ \\
\hline
\end{tabular}

\section{CONCLUSION}

Special migraine preventive medication is now available in the form of subcutaneous and intravenous injections with extended intervals of 1-3 months, making monoclonal antibody therapy against CGRP and CGRP receptors the optimal alternative for individuals with chronic and episodic headaches. Additionally, monoclonal antibodies have 
the benefit of having few side effects and providing excellent therapeutic efficacy, making them a viable alternative for migraine preventive treatment.

\section{Conflict of Interest}

The authors state that they have no conflicting interests.

\section{Acknowledgement: None}

\section{Conflict of Interest: None}

\section{Source of Funding: None}

Ethical Approval: Not Applicable

\section{REFERENCES}

1. Goadsby PJ, Reuter U, Hallström Y, Broessner G, Bonner JH, Zhang F, dkk. A controlled trial of erenumab for episodic migraine. N Engl J Med. 2017;377(22): 2123-2132.

2. Tso AR, Goadsby PJ. Anti-CGRP monoclonal antibodies: the next era of migraine prevention? Curr Treat Options Neurol. 2017;19(8):27.

3. Mattiuzzi C, Lippi G. Updates on migraine epidemiology. Eur $\mathrm{J}$ Neurol. 2020;27(3):e13-e13.

4. Burch RC, Buse DC, Lipton RB. Migraine: Epidemiology, Burden, and Comorbidity. Neurol Clin. 2019;37(4): 631-649.

5. Adnyana IMO. Prevalensi, karakteristik dan beberapa faktor yang berkaitan dengan nyeri kepala migren pada mahasiswa stikes bali. Neurona Maj Kedokt Neuro Sains Perhimpun Dr Spes Saraf Indones. 2012;29(3).

6. Adnyana IMO, Widyadharma IPE, Laksmidewi AAAP, Gelgel AM, Agus K, Naryana S. High serum level of calcitonin gene-related peptide (CGRP) as risk factor for chronic tension type headache on medical students of Udayana University. Age YearspmSD. 2020;19(77):0-73.

7. Cauchi M, Robertson NP. CGRP and migraine. J Neurol. 2016;263(1):192-194.

8. Urits I, Jones MR, Gress K, Charipova K, Fiocchi J, Kaye AD, dkk. CGRP antagonists for the treatment of chronic migraines: a comprehensive review. Curr Pain Headache Rep. 2019;23(5):29.

9. Andreou AP, Edvinsson L. Mechanisms of migraine as a chronic evolutive condition. J Headache Pain. 2019;20(1):117.

10. Burgos-Vega C, Moy J, Dussor G. Meningeal afferent signaling and the pathophysiology of migraine. Dalam: Progress in molecular biology and translational science. Elsevier; 2015. hlm. 537-564.

11. Karsan N, Goadsby PJ. Calcitonin generelated peptide and migraine. Curr Opin Neurol. 2015;28(3):250-254.

12. Goldberg SW, Silberstein SD. Targeting CGRP: a new era for migraine treatment. CNS Drugs. 2015;29(6):443-452.

13. Karsan N, Goadsby PJ. CGRP mechanism antagonists and migraine management. Curr Neurol Neurosci Rep. 2015;15(5):25.

14. Bigal ME, Walter S, Rapoport AM. Calcitonin gene-related peptide (CGRP) and migraine current understanding and state of development. Headache J Head Face Pain. 2013;53(8):1230-1244.

15. Edvinsson L, Haanes KA, Warfvinge K, Krause DN. CGRP as the target of new migraine therapies - successful translation from bench to clinic. Nat Rev Neurol. 2018;14(6):338-350.

16. Krishnaswamy R, Malik BH, Khan S, Gupta D, Islam M, M SK, dkk. AntiCGRP monoclonal antibodies: breakthrough in migraine therapeutics [Internet]. Progress in Neurology and Psychiatry. [dikutip 22 Juni 2020]. Tersedia pada: https://www.progressnp.com/article/anticgrp-monoclonal-antibodiesbreakthrough-in-migraine-therapeutics/

17. Dhillon S. Eptinezumab: First Approval. Drugs. 2020;80:733-739.

18. King CT, Gegg CV, Hu SN-Y, Sen Lu H, Chan BM, Berry KA, dkk. Discovery of the migraine prevention therapeutic Aimovig (erenumab), the first FDAapproved antibody against a G-proteincoupled receptor. ACS Publications; 2019.

19. Garland SG, Smith SM, Gums JG. Erenumab: a first-in-class monoclonal 
antibody for migraine prevention. Ann Pharmacother. 2019;53(9):933-939.

20. Markham A. Erenumab: First global approval. Drugs. 2018;78(11):1157-1161.

21. Hoy SM. Fremanezumab: first global approval. Drugs. 2018;78(17):1829-1834.

22. Lamb YN. Galcanezumab: First global approval. Drugs. 2018;78(16):1769-1775.

23. Stauffer VL, Wang S, Voulgaropoulos M, Skljarevski V, Kovacik A, Aurora SK. Effect of galcanezumab following treatment cessation in patients with migraine: results from 2 randomized phase 3 trials. Headache $\mathrm{J}$ Head Face Pain. 2019;59(6):834-847.

How to cite this article: I Made Oka Adnyana, Faldi Yaputra. Monoclonal antibody therapy: breakthrough in migraine preventive therapy. International Journal of Research and Review. 2022; 9(2): 425-431. DOI: https:// doi.org/10.52403/ijrr.20220254 